\title{
PEMAHAMAN INTERNET SEBAGAI PEMODERASI PENERAPAN SISTEM E-FILLING TERHADAP KEPATUHAN WAJIB PAJAK PADA KPP PRATAMA TABANAN
}

\author{
I Dewa Gede Satria Nugraha ${ }^{1}$ \\ I.D.A.M Manik Sastri ${ }^{2}$ Ni Luh Putu Mita Miati ${ }^{3}$
}

Program Studi Akuntansi

Fakultas Ekonomi dan Bisnis Universitas Warmadewa, Bali-Indonesia

Email: dewasatria0207@gmail.com

\begin{abstract}
Abstrak
Penelitian ini berjudul "Pemahaman Internet sebagai Pemoderasi Penerapan Sistem E-filling Terhadap Kepatuhan Wajib Pajak Pada KPP Pratama Tabanan". Tujuan dari penelitian ini adalah untuk menguji secara empiris pengaruh masingmasing variabel yaitu Pemahaman Internet sebagai Pemoderasi Penerapan Sistem E-filling Terhadap Kepatuhan Wajib Pajak Pada KPP Pratama Tabanan.Teknik pengambilan sampel dilakukan dengan teknikaccidental sampling.Populasi dalam penelitian ini adalah wajib pajak orang pribadi yang terdaftar di KPP Pratama $\begin{array}{lll}\text { Tabanan dan responden yang dijadikan sebagai sampel sebanyak } & 100\end{array}$ responden. Metode analisis data yang digunakan adalah regresi linier sederhana dan Moderated Regression Analysis (MRA). Hasil penelitian menunjukan bahwa penerapan sistem $e$-filling terhadap kepatuhan wajib pajak berpengaruh positif pemahaman internet memoderasi (memperlemah) pengaruh penerapan sistem efilling terhadap kepatuhan wajib pajak.
\end{abstract}

Kata kunci: penerapan $e$-filling, pemahaman internet, kepatuhan wajib pajak

\begin{abstract}
This study is entitled "Understanding the Internet as a Moderating Application of E-filling Systems Against Taxpayer Compliance in Tabanan Primary Tax Office". The purpose of this study is to empirically test the effect of each variable, namely Internet Understanding as a Moderating Application of E-filling Systems to Taxpayer Compliance in the Primary Tax Office. The sampling technique is done by accidental sampling technique. Population in this study is the individual taxpayer registered in KPP Pratama Tabanan and respondents who were sampled as many as 100 respondents. The data analysis method used is simple linear regression and Moderated Regression Analysis (MRA). The6results of the study show that the application of e-filling systems to
\end{abstract}


taxpayer compliance has a positive effect on understanding the internet moderating (weakening) the effect of applying e- filling systems to taxpayer compliance.

Keywords: application of e-filling, internet understanding, taxpayer compliance.

\section{PENDAHULUAN}

Pemerintah Indonesia pada saat sekarang terus berupaya meningkatkan kesejahteraan kehidupan masyarakatnya. Upaya mensejahterahkan masyarakat dalam bentuk peningkatan kemampuan sumber daya manusia dan membangun infrastruktur dimana sebagian besar pembiayaan tersebut, bersumber dari penerimaan pajak. Kepatuhan perpajakan untuk di daerah Bali dikatakan baik tetapi masih banyak aspek yang belum terlaksana guna menumbuhkan kesadaran perpajakan bagi wajib pajak.

Sistem pelaporan SPT di KPP Pratama Tabanan telah menggunakan sistem e-filling, akan tetapi pada kenyataannya pada tahunR2018 telah merealisasikan sebanyak 17.918 wajib pajak terlapor melaui $e$-filling dari jumlah keseluruhanR117.288 wajib pajak terdaftar. Peningkatan pelayanan perpajakanini dilihat dengan berkembangkannya administrasi perpajakan modern dan teknologi informasi di berbagai aspek kegiatan perpajakan. Salah satu bentuk modernisasi sistem administrasi perpajakan yaitu $e$-filing. E-filing merupakan cara penyampaian e-SPT secara online yang real time melalui internet pada website Direktorat Jenderal Pajak (DJP)atau melalui Penyedia Jasa Aplikasi yang dituntuk oleh DJP. Internet menjadi media pendukung sistem e-filing, dimana dalam penggunaan sistem efiling dibutuhkan pemahaman internet yang baik. Hal ini juga menjadi faktor penting wajib pajak untuk menggunakan e-filing, karena dengan pemahaman internet yang baik semakin tinggi pula keinginan wajib pajak dalam menggunakan e-filing. 


\section{TINJAUAN PUSTAKA}

a. Teori Perilaku Perencanaan (Theory of Planned Behavior atau TPB)

Teori Perilaku Perencanaan (Theory of Planned Behavior atau TPB) dirancang untuk memprediksi dan menjelaskan perilaku manusia dalam konteks tertentu(Ajzen, 1991) dalam Rima(2017). Dalam teori ini berupaya untuk memprediksi dan menjelaskan perilaku manusia.

\section{b. Teori Pembelajaran Sosial}

Teori pembelajaran sosial relevan untuk menjelaskan perilaku wajib pajak dalam memenuhi kepatuhan melaporkan pajak. Teori ini diadopsi untuk menjelaskan bahwa wajib pajak akan patuh dalam pelaporan pajak jika lewat pemahaman internet penggunaan sistem e-filling akan mempermudah penggunaannya.

\section{c. Pajak}

Pasal F UU No. 16 tahun 2009 tentang KUP berbunyi: "Pajak adalah kontribusi wajib kepada negara yang terutang oleh pribadi atau badan yang bersifat memaksa berdasarkan undangundang, dengan tidak mendapat imbalan secara langsung dan digunakan untuk keperluan negara bagi sebesar-besarnya kemakmuran rakyat".

\section{d. Penerapan Sistem E-felling}

E-filling adalah suatu cara penyampaian SPT yang dilakukan melalui sistem online dan realtime menurut Fidel (2010: 56)dalam Sari (2015). E-filling sebagai sebuah layanan penyampaian SPT secara elektronik baik untuk Orang Pribadi maupun Badan melalui internet. Penerapan sistem e-filling adalah suatu proses atau cara memanfaatkan sistem yang digunakan untuk menyampaikan SPT secara online yang realtime yang diterapkan oleh Direktorat Jenderal Pajak. 


\section{e. Pemahaman Internet}

Internet merupakan suatu hubungan berbagai jenis komputer dan juga dengan jaringan di dunia yang memiliki sistem operasi dan juga aplikasi yang berbeda, dimana hubungan tersebut memanfaatkan kemajuan perangkat komunikasi semacam telepon dan satelit yang memakai protokol standar dalam melakukan hubungan komunikasi, yaitu protokol TCP/IPW (TransmissionControl/Internet Protocol).

\section{METODE PENELITIAN}

Penelitian ini dilakukan di KPP Pratama Tabanan yang beralamat di Jalan Gatot Subroto Sanggulan, Kecamatan Kediri, Kabupaten Tabanan. Obyek penelitian dari penelitian ini adalah Wajib pajak orang pribadi yang ada di KPP Pratama Tabanan. Populasi dalam penelitian ini adalah seluruh wajib pajak orang pribadi yang terdaftar di KPP Pratama Tabanan tahun 2018 yang berjumlah 125.643 WPO. Penelitian ini menggunakan teknik nonprobability sampling yaitu dengan teknik accidentalsampling.

\section{HASIL DAN PEMBAHASAN}

\section{Analisi Data}

\section{Uji Instrumen}

\section{a. Uji Validitas}

keseluruhan indikator yang digunakan pada masing-masing variabel memiliki nilai Pearson Correlation diatas 0,3 sehingga keseluruhan indikator yang digunakan tersebut dinyatakan valid. 


\section{b. Uji Reliabilitas}

Tabel 11

Hasil Uji Reliabilitas

\begin{tabular}{|l|c|c|}
\hline \multicolumn{1}{|c|}{ Variabel } & Cronbarch's Alpha & Keterangan \\
\hline Penerapan Sistem $e$-filling(X) & 0,757 & Reliabel \\
\hline $\begin{array}{l}\text { Kepatuhan Wajib Pajak Orang } \\
\text { Pribadi (Y) }\end{array}$ & 0,761 & Reliabel \\
\hline Pemahaman Internet (Z) & 0,791 & Reliabel \\
\hline
\end{tabular}

Sumber: Data diolah, 2020

Memiliki nilai Cronbarch's Alpha untuk setiap variabel adalah lebih besar dari 0,70. Hal ini berarti bahwa pernyataan dalam kuesioner yang digunakan adalah reliabel.

\section{Uji Asumsi Klasik}

\section{Uji multikoliniaritas}

\section{Tabel 12}

\section{Hasil Uji Multikolinearitas}

\begin{tabular}{|l|c|c|}
\hline \multicolumn{1}{|c|}{ Variabel } & Tolerance & VIF \\
\hline Penerapan Sistem E-filling(X) & 0,767 & 1,305 \\
\hline Pemahaman Internet $(\mathrm{Z})$ & 0,767 & 1,305 \\
\hline
\end{tabular}

Sumber: Data diolah, 2020

$$
\text { Berdasarkan hasil uji multikolonieritas pada tabel } 12
$$

menunjukkan bahwa masing-masing variabel memiliki nilai Variance Inflation Factor (VIF) yang kurang dari 10 . Nilai Tolerance diatas $10 \%$ atau 0,1. Maka dapat disimpulkan bahwa tidak terjadi hubungan multikolonieritas antara variabel bebas tersebut. 


\section{Uji Heteroskedastisitas}

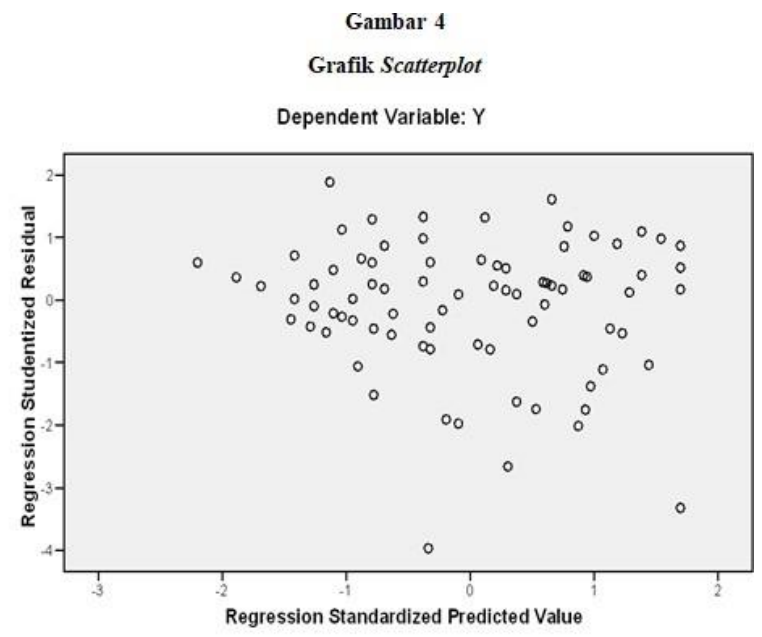

Sumber: Data diolah, 2020

Grafik Scatterplot menunjukkan model regresi penelitian ini tidak mempunyai gangguan heteroskedastisitas karena terlihat dari titiktitik yang menyebar secara acak, tidak membentuk suatu pola tertentu yang jelas, serta tersebar baik di atas maupun dibawah angka $0 \quad$ (nol) pada sumbu $Y$, ini berarti tidak ada heteroskedastisitas sehingga model regresi layak digunakan untuk memprediksi variabel dependen. 
Tabel 13

Hasil Uji Normalitas

\begin{tabular}{|l|r|r|}
\hline \multicolumn{3}{|c|}{ One-Sample Kolmogorov-Smirnov Test } \\
\hline $\mathrm{N}$ & $\begin{array}{r}\text { Unstandardiz } \\
\text { ed Residual }\end{array}$ \\
Normal Parameters a,b & $\begin{array}{r}100 \\
\end{array}$ & .0000000 \\
Most Extreme & Std. Deviation & 2.89474706 \\
Differences & Absolute & .121 \\
& Positive & .071 \\
Kolmogorov-Smirnov Z & Negative & -.121 \\
Asymp. Sig. (2-tailed) & & 1.212 \\
\end{tabular}

a. Test distribution is Normal.

b. Calculated from data.

Sumber: Data diolah, 2020

Tabel 13 menunjukkan bahwa nilai Kolmogorov-Smirnov $Z$ sebesar 1,121 dengan koefisien Asymp. Sig (2-tailed) lebih besar dari 0,05 yaitu sebesar 0,106 sehingga dapat disimpulkan bahwa data terdistribusi dengan normal.

Uji $\mathbf{t}$

1. Pengaruh Penerapan Sistem e-filling pada Kepatuhan Wajib Pajak

Tabel 14

Hasil Perhitungan Hipotesis 1

\begin{tabular}{|c|c|c|c|c|c|c|}
\hline \multicolumn{2}{|c|}{ Nilai r } & \multicolumn{2}{|c|}{ Nilai t } & \multirow[t]{2}{*}{ Sig. } & \multirow{2}{*}{$\begin{array}{c}\text { Konstanta } \\
(\alpha)\end{array}$} & \multirow{2}{*}{$\begin{array}{c}\text { Koefisien } \\
(\beta)\end{array}$} \\
\hline $\begin{array}{c}\mathrm{r} \\
\text { hitung }\end{array}$ & $\mathrm{r}^{2}$ & $\begin{array}{c}\mathrm{T} \\
\text { hitung }\end{array}$ & $\begin{array}{c}\mathrm{t} \\
\text { tabel }\end{array}$ & & & \\
\hline 0,568 & 0,323 & 6,839 & 1,66023 & 0,000 & 25,815 & 0,568 \\
\hline
\end{tabular}

Sumber: Data diolah, 2020 
$\mathrm{Y}=25,815+0,568 \mathrm{X}$

Persamaan tersebut menunjukkan bahwa konstanta sebesar 25,815

hal ini menunjukkan bahwa apabila variabel $\mathrm{X}$ dianggap nol, maka

nilai variabel Kepatuhan Wajib Pajak adalah sebesar 25,815

satuan. Koefisien regresi $\mathrm{X}$ sebesar 0,568menunjukkan bahwa

setiap kenaikan Penerapan Sistem e-fillingsebesar 1 satuan akan

menaikkan kepatuhan wajib pajak sebesar 0,568 satuan.

\section{Pengaruh Pengaruh Penerapan Sistem e-filling pada Kepatuhan Wajib} Pajak dengan Pemahaman Internet sebagai Variabel Pemoderasi

Tabel 15

\begin{tabular}{|c|c|}
\hline Variabel & Koefision Regresi \\
\hline Penerapan Sistem E-filling & 0,459 \\
\hline Pemahaman Internet & 0,193 \\
\hline Moderated Regression Analysis & $-0,188$ \\
\hline $\mathrm{R}$ & 0,618 \\
\hline R Square & 0,381 \\
\hline F Hitung & 19,724 \\
\hline Sig F & 0,000 \\
\hline Sig Penerapan Sistem E-filling & 0,000 \\
\hline Sig Pemahaman Internet & 0,039 \\
\hline SigModerated Regression Analysis & 0,022 \\
\hline
\end{tabular}

Sumber: Data diolah, 2020

$$
\mathrm{Y}=0,459 \mathrm{X} 1+0,193 \mathrm{Z}-0,188 \mathrm{X} 1 \mathrm{Z}
$$

Penerapan sistem e-filling sebesar 0.459 dan menunjukan arah positif. Koefisien regresi pada pemahaman internet sebesar 0,193 dan menunjukan arah positif. interaksi antara penerapan sistem $e$ filling dan pemahaman internet) sebesar $-0,188$ dan menunjukan arah negatif.

\section{PEMBAHASAN}

penerapan sistem $e$-filling berpengaruh positif dan signifikan terhadap kepatuhan wajib pajak. Hal ini dapat dibuktikan dengan nilai t hitung 6,839 yang lebih besar dari t tabel 1,660 dengan nilai 
signifikansi sebesar 0,000 lebih kecil dari 0,05. Nilai koefisien regresi sebesar 0,568 yang memiliki arah positif hipotesis kedua yang menyatakan pemahaman internet dapat memoderasi pengaruh penerapan sistem e-filling terhadap kepatuhan wajib pajak. Hal ini dapat dibuktikan dengan nilai $\mathrm{F}$ hitung 19,724 yang lebih besar dari F tabel 3,94 dengan nilai signifikansi sebesar 0,000 lebih kecil dari 0,05. Hasil penelitian ini mengindikasikan bahwa pemahaman internet memperlemah pengaruh penerapan sistem e-filling terhadap kepatuhan wajib pajak. semakin baik pemahaman internet yang dimiliki wajib pajak maka akan mendorong wajib pajak untuk mengg[unakan sistem e-filling sehingga semakin meningkatkan kepatuhan wajib pajak.

\section{PENUTUP}

\section{Simpulan}

Simpulan dari penelitian ini adalah sebagai berikut:

a. Terdapat pengaruh positif dan signifikan dari penerapan sistem $e$-filling terhadap kepatuhan wajib pajak. Hal ini dikarenakan penerapan sistem $e$ filling dapat memberikan manfaat dan kontribusi yang baik bagi wajib pajak.

b. Pemahaman Internet dapat memoderasi(memperlemah) pengaruh penerapan sistem e-filling terhadap kepatuhan wajib pajak. Hal ini disebabkan karena pemahaman internet adalah faktor yang menunjang penerapan sistem $e$-fillingterhadap kepatuhan wajib pajak.

\section{Saran}

Berdasarkan hasil pada simpulan diatas, maka saran yang dapat diberikan adalah sebagai berikut:

1. Bagi Wajib Pajak

Untuk wajib pajak diharapkan lebih efektif dalam mencari informasi mengenai perpajakan melalui internet agar wajib pajak tidak perlu 
ke KPP Pratama untuk mengantri melaporkan SPT melaui sistem $e$ filling.

2. Kantor Pelayanan Pajak Pratama Tabanan diharapkan lebih sering turun ke masyarakat atau jemput bola untuk meningkatkan kepatuhan wajib pajak orang pribadi dalam melaporkan SPT melaluiKsistem $e$-filling.

\section{DAFTAR PUSTAKA}

Abdul Rahman. (2010). Panduan Pelaksanaan Administrasi Perpajakan Untuk Karyawan, Pelaku Bisnis dan Perusahaan. Bandung : Nuansa.

Ajzen, I. (1991). The theory of planned behavior. Organizational Behavior and Human Decision Processes, 50(2), 179-211.

Budiantara, Yuliano Osvaldo Lado\& M., (2018). "Pengaruh Penerapan Sistem EFilling Terhadap Kepatuhan Wajib Pajak Orang Pribadi Pegawai Negeri Sipil Dengan Pemahaman Internet Sebagai Variabel Pemoderasi (Studi Kasus Pada Dinas Perindustrian Dan Perdagangan DIY)". Program Studi Akuntansi FE Universitas Mercu Buana Yogyakarta.

Dewi, Ni Putu Vivi Yuliana (2018). "Pengaruh Pemahaman Perpajakan, Sanksi

Pajak, Pemeriksaan Pajak, Biaya Kepatuhan Pajak dan Tax Amnesty Terhadap Kepatuhan Wajib Pajak Badan di Kantor Pelayanan Pajak Pratama Tabanan" Program Studi Akuntansi Fakultas Ekonomi Universitas Warmadewa.

Fidel, (2010). Cara Mudah dan Praktis Memahami Masalah-Masalah Perpajakan. Jakarta: Muria Kencana.

Hartono, J.(2007). Sistem informasi keperilakuan. Yogyakarta: Andi Offset.

Lingga, Sri Rahayu \& Ita Salsalina Lingga. (2009). "Pengaruh Modernisasi Sistem Administrasi Perpajakan terhadap Kepatuhan Wajib Pajak". Jurnal Akuntansi. Vol.1, No:119-138.

Mardiasmo. (2016). Perpajakan edisi Terbaru 2016.Yogyakarta: C.V Andi Offset 